\title{
Inflammatory markers and retinopathy in pregnancies complicated with Type I diabetes
}

${ }^{1}$ Department of Ophthalmology Helsinki University Central Hospital Helsinki, Finland

${ }^{2}$ Department of Obstetrics and Gynaecology Helsinki University Central Hospital Helsinki, Finland

Correspondence: S Loukovaara Department of Ophthalmology Helsinki University Central Hospital Haartmaninkatu $4 \mathrm{C}$ FIN-00290 Helsinki Finland Tel: + 358947173131 Fax: + 358947175100 E-mail: sirpa.loukovaara@ hus.fi

Received: 30 June 2003 Accepted: 2 February 2004 Published online: 30 July 2004

None of the authors has a proprietary interest.

\begin{abstract}
Aim The relation of maternal cytokine levels to retinopathy progression during diabetic pregnancy is a less studied subject. Therefore, we investigated levels of systemic proinflammatory markers, C-reactive peptide (CRP), interleukin-6 (IL-6) and circulating vascular cell adhesion molecule-1 (VCAM-1) during pregnancy and postpartum in relation to the progression of diabetic retinopathy (DR).

Methods A prospective follow-up study of 39 pregnant women with Type I diabetes and eight nondiabetic pregnant women was performed. DR was graded from fundus photographs. Plasma levels of systemic proinflammatory markers were measured by immunofluorometric assay (CRP) and by enzyme-linked immunosorbent assay (IL-6 and VCAM-1) in the first, second (diabetics only), third trimester of pregnancy, and 3 and 6 months postpartum (diabetics only). Results Our diabetic women had good glycaemic control (HbA1c $6.9 \pm 0.8$ ). The levels of IL-6, VCAM-1, and CRP did not differ between diabetic and nondiabetic women throughout pregnancy and postpartum (repeated measures ANOVA between the groups). An association between CRP and progression of retinopathy was observed in diabetic women $(P=0.037)$. Additional evidence of inter-relationship could be revealed as CRP was higher in those diabetic women with worse glycaemic control (HbA1c) $(P=0.038)$.

Conclusions During pregnancy and postpartum, levels of proinflammatory factors (IL-6, CRP, VCAM-1) seem to be generally similar in Type I diabetic women compared to nondiabetic controls. However, CRP levels
\end{abstract}

S Loukovaara', I Immonen', R Koistinen², $\checkmark$ Hiilesmaa ${ }^{2}$ and $R$ Kaaja $^{2}$

were higher in those diabetic women with progression of retinopathy and in those with worse glycaemic control.

Eye (2005) 19, 422-430. doi:10.1038/sj.eye.6701499 Published online 30 July 2004

Keywords: inflammatory mediators; VCAM-1; interleukin-6; cytokines; CRP; diabetic retinopathy; diabetic pregnancy; Type I diabetes

\section{Introduction}

During pregnancy, physiological changes occur in the cardiovascular, hormonal, metabolic, haematologic, and immunologic systems. ${ }^{1} \mathrm{By}$ some of these mechanisms, pregnancy can exacerbate the background retinopathy in diabetic women even when good metabolic control is achieved and retinopathy is minimal before pregnancy. ${ }^{2}$

Elevated levels of inflammatory mediators have been associated with Type I diabetes ${ }^{3,4}$ and in the pathogenesis of diabetic retinopathy (DR), especially in proliferative DR. ${ }^{5}$ Increased inflammation during the first trimester has been shown to play a role in women who develop gestational diabetes. ${ }^{6}$ Systemic endothelial cell dysfunction, such as modified release of soluble leucocyte adhesion molecules, with immunoinflammatory events may play a role in the progression of DR during pregnancy.

Previously, we demonstrated that retinal blood flow is increased during diabetic pregnancy. ${ }^{7}$ In an experimental study, leukostasis was shown to be associated with endothelial dysfunction, but not with retinal blood flow. ${ }^{8}$ There is a possibility that increased levels of proinflammatory factors, derived from the blood by the breakdown of blood-retinal 
barrier could be associated with the grade or progression of retinopathy during pregnancy and degree of retinal blood flow. Accordingly, we determined the role of Creactive protein $(\mathrm{CRP})$, proinflammatory cytokine interleunkin-6 (IL-6), and Vascular cell adhesion molecule-1 (VCAM-1) in a group of diabetic and nondiabetic women and studied if there is any correlation between these markers and stage or progression of retinopathy during pregnancy and postpartum.

\section{Material and methods}

The study was carried out with the approval of the local institutional review board, in accordance with the tenets of the Declaration of Helsinki. Written informed consent was obtained from all the participants.

\section{Pregnant diabetic women}

From November 1998 to January 2002, 72 consecutive women with Type I diabetes were recruited to the study at the Department of Obstetrics and Gynaecology, Helsinki University Central Hospital, as soon as their pregnancy was diagnosed (usually between 5 and 10 weeks of gestation). The women were then referred to the Department of Ophthalmology, where they were studied at the 12th-14th week, 24th-26th week, and 34th-36th week of gestation, and at 3 and 6 months postpartum. All of them were treated with long-acting insulin 2-3 times a day. Short-acting insulin was given before meals.

Nine women were excluded, either because of obstetric complications or coexisting eye disease: one due to spontaneous abortion, one for an induced abortion due to a high glycosylated haemoglobin level (12-13\%), six for preterm delivery, and one for retinitis pigmentosa. Thus, after exclusion of nine women, 63 diabetic women were available for clinical characteristics. Six diabetic women had received panphotocoagulation before current pregnancy, and therefore they were excluded from the analysis. Additionally, the lack of complete follow-up data of all proinflammatory measurements (technical reasons due to inadequate quantity of samples, broken/lost tubes etc) reduced the number of the diabetic women to 39 in the final analysis. Two diabetic women had diabetic nephropathy defined as albumin excretion rate $\geqslant 0.3 \mathrm{~g} / 24 \mathrm{~h}$ on two consecutive visits. ${ }^{9}$ Both women with nephropathy had a normal endogenous creatinine clearance.

\section{Nondiabetic pregnant women}

A total of 15 nondiabetic pregnant women in the same age range attending the Department of Obstetrics and
Gynaecology for monitoring of normal pregnancy could be recruited to participate in the study. Of the 15 controls, four were unable to attend all eye examinations because of obstetric complications such as early fetal loss, preeclampsia, preterm uterine contractions, and preterm delivery. Missing laboratory samples/inadequate quantity of samples reduced the total amount of controls to eight in the final statistical analysis. Nondiabetic controls were examined during the first and third trimester, and at 3 months postpartum.

All nondiabetic subjects had corrected visual acuities of $6 / 6$ or better, normal ocular examination results, and no history of eye disease.

\section{Ophthalmological examination}

Each study subject underwent a complete ophthalmological examination including measurement of visual acuity, biomicroscopic examination by indirect ophthalmoscopy, and fundus photography. The intraocular pressure of each participant, measured with a Goldmann applanation tonometer, was below $21 \mathrm{mmHg}$.

\section{Fundus photography}

Fundus photography of both eyes was performed through dilated pupils (by the use of two drops of tropicamide, $5 \mathrm{mg} / \mathrm{ml}$ ) by a trained operator using a Topcon TRC 50IA retinal camera (Topcon Corporation, Tokyo, Japan) and Kodak Elitechrome 100 film (Eastman Kodak, Rochester, NY, USA). The severity of DR was assessed using two $50^{\circ}$ colour slides, one centred at the macula and the other at the optic nerve head. Ocular history, including laser photocoagulation treatment, was checked in hospital records.

The photographs were evaluated by a retinal specialist (II), masked to all clinical information. Retinopathy (RP) was graded by a modification of the Early Treatment Diabetic Retinopathy Study (ETDRS) grading system, with ETDRS standard pictures being used for grading the severity of retinopathy. ${ }^{10}$ For each eye, the maximum grade of retinopathy lesions was determined to produce the overall severity level for that eye (RP level). Retinal findings were classified into the following groups: (1) no retinopathy (RP level 10), (2) very mild retinopathy (RP level 20), (3) mild retinopathy (RP level 35), (4) moderate retinopathy (RP level 43), (5) moderate retinopathy, more extensive intraretinal microvascular abnormalities (IRMAs) (RP level 47), (6) severe nonproliferative retinopathy (RP level 53), and (7) proliferative retinopathy (RP level $>53$ ). All colour fundus photographs from nondiabetic subjects were graded as RP level 10 in the masked grading. Finally, the retinopathy levels from both eyes were combined to give 
a final score of retinopathy severity for each patient (scale 1-11 according to the Diabetes Control and Complications Trial (DCCT), where a score of 1 means no retinopathy and a score of 11 indicates proliferative retinopathy. ${ }^{11}$ Progression of retinopathy was classified as follows: (1) no progression in retinopathy, when there was no change or a decrease in DCCT score during pregnancy from the first to the third trimester, and (2) any progression, if DCCT score increased by one or more levels during pregnancy.

\section{Confocal scanning laser Doppler flowmetry}

Measurements of retinal capillary blood flow were performed by confocal scanning laser Doppler flowmetry using the Heidelberg Retinal Flowmeter (HRF, Heidelberg Engineering $\mathrm{GmbH}$, Heidelberg, Germany). ${ }^{7}$ The mean values of the 75 th percentile of the individual-pixel point-wise analysis were correlated with mean concentrations of proinflammatory markers during pregnancy and postpartum. The diabetic women were divided into two groups depending on the mean retinal capillary blood flow value ( $\leqslant 363$ and $>363$ in AU) in the first trimester. In addition, the blood flow values of the diabetic women were divided into quartiles: the highest quartile (25\%) was compared with the three lower quartiles (75\%).

\section{Measurement of serum glycosylated haemoglobin concentration}

Serum glycosylated haemoglobin (HbA1c) concentrations were measured by ion-exchange highperformance liquid chromatography (Diamat, Bio-Rad Laboratories, Hercules, CA, USA). Four values of $\mathrm{HbA1c}$ were used in the study, that is, the mean values of all $\mathrm{HbA} 1 \mathrm{c}$ measurements taken during the first (7.3 \pm 0.8$)$, second $(6.6 \pm 0.8)$, and third trimester $(6.9 \pm 0.9)$, as well as mean value for whole pregnancy $(6.9 \pm 0.8)$.

The blood glucose level in diabetic women were followed up by a fingertip prick and a blood glucose meter (Glucometer Elite, Bayer Diagnostics, Fernwald, Germany).

\section{Measurement of proinflammatory markers}

Venous blood samples were drawn from diabetic women at the end of each trimester, at gestational weeks 12-14, 24-26, 34-36, and 3 and 6 months postpartum, and from nondiabetic controls at gestational weeks $12-14,34-36$, and 3 months postpartum. Blood was drawn from the antecubital vein into chilled tubes by a trained nurse with subjects in the upright position by careful venepuncture (avoiding haemolysis). The samples were centrifuged at $7000 \mathrm{rpm}$ for $10 \mathrm{~min}$ at $4^{\circ} \mathrm{C}$ and were immediately frozen and stored at $-70^{\circ} \mathrm{C}$ until assayed, and then were measured in a single assay to avoid interassay variability.

C-reactive protein (CRP) $(\mathrm{mg} / \mathrm{l})$ concentrations were measured by immunofluorometric assay (IFMA, Medix Biochemica, Kauniainen, Finland). ${ }^{12,13}$ The detection limit is $0.03 \mathrm{mg} / \mathrm{l}$ and the interassay coefficient of variation $<10 \%$ in the concentration range of $0.1-120 \mathrm{mg} / \mathrm{l}$.

Interleukin-6 (IL-6) (pg/ml) was quantified by highsensitivity enzyme-linked immunosorbent assay (ELISA) according to the manufacturer's instructions (Quantikine HS hIL-6, R\&D Systems Europe Ltd, Abingdon, UK).

Soluble vascular cell adhesion molecule-1 (sVCAM-1) $(\mathrm{ng} / \mathrm{ml})$ was measured by high-sensitivity ELISA (BioSource Europe SA, Nivelles, Belgium). ${ }^{14}$

\section{Subgroup analysis}

Levels of proinflammatory markers were compared between subgroups according to the following criteria: (1) retinopathy level in the first trimester (DCCT score $\leqslant 3$ compared to DCCT score $>3$ ), (2) progression of DR (no progression in DCCT score compared to progression in DCCT score) during pregnancy, or (3) mean HbA1c value $<6.9 \%$. or $\geqslant 6.9 \%$ during pregnancy.

In addition, the diabetic women were divided into subgroups to study the effects of progression to proliferative retinopathy, duration of diabetes $<16$ years or $\geqslant 16$ years, macrosomia, development of preeclampsia, nephropathy, smoking, or mean systolic and diastolic blood pressure $(\mathrm{mmHg})$ in the third trimester.

\section{Statistical analysis}

Statistical analysis were performed with the SPSS software version 9.0. for Windows (SPSS Inc., Chicago, IL, USA). Variables were tested for normality. The MannWhitney $U$-test was used for non-normally distributed continuous variables. Analysis of variance and covariance (ANOVA) with repeated measures were performed to study temporal changes in CRP, IL-6, and VCAM-1 during pregnancy and postpartum between diabetic and nondiabetic women. Skewness of CRP, IL-6, and VCAM-1 data was corrected by logarithmic transformation. Bonferroni correction was used for multiple group comparisons. Multivariate logistic regression analysis with retinopathy final scale (stable DCCT score or worsening DCCT score) as the dependent variable was performed with enter procedure. A $P$-value of $<0.05$ was considered statistically significant. 


\section{Results}

Baseline characteristics of the two groups are summarized in Table 1.

Of the 39 diabetic women with proinflammatory measurements available, $23(59 \%)$ had no or mild retinopathy (DCCT score $\leqslant 3$ ) and $16(41 \%)$ had more severe retinopathy (DCCT score $>3$ ) in the first trimester. By the third trimester, $16(41 \%)$ of the women had a DCCT score $\leqslant 3$, and $23(59 \%)$ a DCCT score $>3$. During pregnancy, $25(64 \%)$ of the diabetic women had no progression in the DCCT score, and 14 (36\%) progressed. Out of these 14 women, four (10\%) progressed one step and $10(26 \%)$ women progressed two or more steps in DCCT scale.

Prior to current pregnancy, four (10\%) diabetic women had received local laser treatment. During our study, four (10\%) diabetic women developed proliferative changes needing subsequent laser treatment. Two of these four developed bilateral neovascularization needing panretinal photocoagulation, and two developed unilateral neovascularization needing sectoral photocoagulation. In addition, one diabetic woman (3\%) received local laser treatment because of leaking microaneurysms in the macula.

\section{Proinflammatory markers in diabetic and nondiabetic women}

Concentrations of proinflammatory factors between the two study groups during pregnancy and postpartum are summarized in Table 2. Although no statistically significant differences appeared between the groups, IL-6 values tended to be higher in diabetic than in nondiabetic women.

Concentrations of these factors according to the baseline severity level of DR are given in Table 3 and according to progression of DR during pregnancy in Table 4. No differences existed in the levels of CRP, IL-6, or VCAM-1 between diabetic subgroups and controls when divided according to either the baseline DCCT score or progression of retinopathy (Tables 3 and 4).

When all the five timepoints at which the diabetic women were studied were taken into account, there was, however, a constant difference in CRP levels, showing statistically significantly higher levels of CRP in those diabetic women with progression of retinopathy (worsening DCCT score) during pregnancy when compared to those women with no progression of DR (stable DCCT score) $(P=0.037)$ (Table 4). Additionally, throughout pregnancy and postpartum, levels of CRP

Table 1 Baseline characteristics of the Type I diabetic and nondiabetic women

\begin{tabular}{|c|c|c|c|}
\hline & Diabetic women $(\mathrm{n}=39)$ & Controls $(\mathrm{n}=8)$ & $\mathrm{P}$ \\
\hline Age (years) & $30.3 \pm 5.0$ & $31.8 \pm 3.3$ & 0.38 \\
\hline Duration of diabetes (years) & $15.1 \pm 7.3$ & & \\
\hline Prepregnancy BMI $\left(\mathrm{kg} / \mathrm{m}^{2}\right)$ & $24.6 \pm 3.4$ & $22.0 \pm 2.1$ & $0.02^{*}$ \\
\hline Duration of pregnancy (days) & $257.5 \pm 6.8$ & $284.1 \pm 5.6$ & $<0.0001^{*}$ \\
\hline Birth weight of the infant $(\mathrm{g})$ & $3675.4 \pm 652.6$ & $3797.1 \pm 497.9$ & 0.73 \\
\hline \multicolumn{4}{|l|}{ Blood pressure $(\mathrm{mmHg})$} \\
\hline Systolic/first trimester (max) & $121.3 \pm 14.0$ & $121.0 \pm 9.2$ & 0.92 \\
\hline Diastolic/first trimester (max) & $75.8 \pm 11.0$ & $74.9 \pm 8.0$ & 0.55 \\
\hline Systolic/third trimester (max) & $139.8 \pm 24.0$ & $123.9 \pm 10.4$ & $0.05^{*}$ \\
\hline Diastolic/third trimester (max) & $83.8 \pm 14.1$ & $81.5 \pm 8.1$ & 0.63 \\
\hline \multicolumn{4}{|l|}{$H b A 1 c(\%)$} \\
\hline First trimester & $7.3 \pm 0.8$ & NA & \\
\hline Second trimester & $6.6 \pm 0.8$ & NA & \\
\hline Third trimester & $6.8 \pm 1.0$ & NA & \\
\hline Mean $\mathrm{HbA} 1 \mathrm{c}(\%)$ during pregnancy & $6.9 \pm 0.8$ & NA & \\
\hline Nephropathy & $2(5.1 \%)$ & & \\
\hline \multicolumn{4}{|l|}{ Retinopathy at baseline } \\
\hline DCCT score 1 & $12(30.8 \%)$ & & \\
\hline DCCT score 2 & $8(20.5 \%)$ & & \\
\hline DCCT score 3 & $3(7.7 \%)$ & & \\
\hline DCCT score 4 & $3(7.7 \%)$ & & \\
\hline DCCT score 5 & $8(20.5 \%)$ & & \\
\hline DCCT score 6 & $3(7.7 \%)$ & & \\
\hline DCCT score 7 & $2(5.1 \%)$ & & \\
\hline
\end{tabular}

Values are mean $\pm \mathrm{SD}$ or $n \%$; $\mathrm{BMI}=$ body mass index; $\mathrm{NA}=$ not applicable; ${ }^{*}$ statistically significant difference. 
Table 2 Concentrations of inflammatory markers in Type I diabetic $(n=39)$ and nondiabetic $(n=8)$ women throughout pregnancy and postpartum

\begin{tabular}{|c|c|c|c|c|}
\hline & First trimester & Third trimester & 3 mo $p p$ & $\mathrm{P}$ \\
\hline \multicolumn{5}{|l|}{$C R P(m g / l)$} \\
\hline Diabetic women & $2.6(1.1-6.0)$ & $2.4(1.4-4.9)$ & $1.6(0.8-3.3)$ & \multirow[t]{2}{*}{0.188} \\
\hline Controls & $2.7(1.5-14.6)$ & $2.5(0.9-4.9)$ & $0.5(0.2-1.3)$ & \\
\hline \multicolumn{5}{|l|}{ IL-6 (pg/ml) } \\
\hline Diabetic women & $1.2(0.7-2.2)$ & $2.7(1.8-4.7)$ & $1.7(1.2-2.2)$ & \multirow[t]{2}{*}{0.216} \\
\hline Controls & $1.2(0.9-1.7)$ & $1.8(0.8-4.1)$ & $1.0(0.6-1.3)$ & \\
\hline \multicolumn{5}{|l|}{$V C A M-1(n g / m l)$} \\
\hline Diabetic women & $573(487-762)$ & $640(506-1080)$ & $631(542-770)$ & \multirow[t]{2}{*}{0.682} \\
\hline Controls & 736 (621-928) & $535(469-665)$ & 765 (630-950) & \\
\hline
\end{tabular}

3 mo $\mathrm{pp}=3$ months postpartum; CRP=C-reactive protein; IL- $6=$ Interleukin-6; VCAM-1 = vascular cell adhesion molecule-1; Values are median (interquartile range); $P$-values were calculated with repeated measures ANOVA; CRP, IL-6, and VCAM-1 values were log-transformed to correct skewness.

Table 3 Concentrations of inflammatory markers in Type I diabetic women with baseline retinopathy level DCCT $\leq 3(n=23)$ compared to those with baseline retinopathy level DCCT $>3(n=16)$ and nondiabetic controls $(n=8)$ throughout pregnancy and postpartum

\begin{tabular}{|c|c|c|c|c|c|c|c|c|}
\hline & First trimester & Second trimester & Third trimester & 3 mo $p p$ & 6 mo $p p$ & $\begin{array}{c}\mathrm{P} \text { (each } \\
\text { diabetic group } \\
\text { vs controls) } \\
\text { three timepoints }\end{array}$ & $\begin{array}{c}\mathrm{P} \text { (between } \\
\text { diabetics) } \\
\text { three } \\
\text { timepoints }\end{array}$ & $\begin{array}{l}\mathrm{P} \text { (between } \\
\text { diabetics) } \\
\text { all five time } \\
\text { timepoints }\end{array}$ \\
\hline \multicolumn{9}{|l|}{$C R P(m g / l)$} \\
\hline $\mathrm{DCCT} \leqslant 3$ & $2.8(1.1-7.6)$ & $4.1(1.6-7.6)$ & $2.6(1.4-5.5)$ & $1.8(1.1-3.6)$ & $1.5(0.5-4.1)$ & 0.259 & 0.454 & 0.212 \\
\hline DCCT $>3$ & $2.2(0.8-4.1)$ & $2.5(1.7-5.5)$ & $2.3(1.3-4.1)$ & $0.9(0.6-3.1)$ & $0.8(0.5-1.3)$ & 1.0 & & \\
\hline Controls & $2.7(1.5-14.6)$ & NA & $2.5(0.9-4.9)$ & $0.5(0.2-1.3)$ & NA & & & \\
\hline \multicolumn{9}{|l|}{$I L-6(p g / m l)$} \\
\hline DCCT $\leqslant 3$ & $1.2(0.8-2.2)$ & $1.6(1.0-2.5)$ & $2.1(1.5-4.5)$ & $1.7(1.2-2.2)$ & $1.3(0.9-2.2)$ & 1.0 & 0.817 & 0.165 \\
\hline $\mathrm{DCCT}>3$ & $1.2(0.6-2.3)$ & $2.2(1.0-2.7)$ & $2.9(2.1-5.4)$ & $1.6(1.1-2.1]$ & $1.8(1.1-3.1)$ & 0.337 & & \\
\hline Controls & $1.2(0.9-1.7)$ & NA & $1.8(0.8-4.1)$ & $1.0(0.6-1.3)$ & NA & & & \\
\hline \multicolumn{9}{|c|}{$V C A M-1(n g / m l)$} \\
\hline $\mathrm{DCCT} \leq 3$ & $569(461-762)$ & 473 (372-629) & $606(492-824)$ & $620(483-881)$ & 617 (475-893) & 1.0 & 1.0 & 0.702 \\
\hline DCCT $>3$ & 609 (556-778) & $481(375-567)$ & $771(558-1134)$ & $662(594-769)$ & $600(484-855)$ & 1.0 & & \\
\hline Controls & 736 (621-928) & NA & $535(469-665)$ & 765 (630-950) & NA & & & \\
\hline
\end{tabular}

3 mo pp=3 months postpartum; CRP = C-reactive protein; IL-6 = Interleukin-6; VCAM-1 = vascular cell adhesion molecule-1; Values are median (interquartile range); $\mathrm{NA}=$ not applicable; $P$-values were calculated with repeated measures ANOVA; CRP, IL-6, and VCAM-values were logtransformed to correct skewness.

were significantly lower and the levels of VCAM-1 were higher in those diabetic women who had mean $\mathrm{HbA} 1 \mathrm{c}$ $<6.9 \%$ during pregnancy than in those with $\geqslant 6.9 \%$ $(P=0.038)$ (Table 5).

IL-6 levels were also significantly lower in those diabetic women, who had the duration of diabetes less than 16 years; $0.9(0.6-1.4)$ in the first trimester, 1.2 (0.91.9) in the second trimester, $2.1(1.4-4.6)$ in the third trimester, $1.4(1.2-1.9)$ at 3 months postpartum, and 1.0 (0.7-1.9) at 6 months postpartum compared with the values of $1.5(0.9-2.5), 2.0$ (1.2-2.8), 3.1 (2.1-4.8), 2.0 (1.2$3.0)$, and $2.3(1.2-3.1)$, respectively, in those with duration of diabetes more than 16 years $(P=0.024)$.

The levels of inflammatory markers did not differ between the diabetic women who progressed to proliferative retinopathy $(n=4)$ during pregnancy compared to those who did not $(n=35)$ (CRP, $P=0.60$; IL-6, $P=0.86$; VCAM-1; $P=0.95)$. No differences in inflammatory markers were found in the subgroups according to macrosomia, development of pre-eclampsia, nephropathy, smoking, or mean systolic and diastolic blood pressure $(\mathrm{mmHg}$ ) in the third trimester (not shown).

\section{Retinal capillary blood flow and proinflammatory markers}

No differences in the levels of proinflammatory markers could be found between the groups, divided according to the mean retinal capillary blood flow in the first trimester 
Table 4 Concentrations of inflammatory markers in Type I diabetic women with no progression of diabetic retinopathy $(n=25)$ during pregnancy compared to those with progression of diabetic retinopathy $(n=14)$ and nondiabetic controls $(n=8)$

\begin{tabular}{|c|c|c|c|c|c|c|c|c|}
\hline & First trimester & Second trimester & Third trimester & 3 mo $p p$ & $6 m o p p$ & $\begin{array}{c}\mathrm{P} \text { (each } \\
\text { diabetic group } \\
\text { vs controls) } \\
\text { three } \\
\text { timepoints }\end{array}$ & $\begin{array}{l}\mathrm{P} \text { (between } \\
\text { diabetics) } \\
\text { three } \\
\text { timepoints }\end{array}$ & $\begin{array}{c}\mathrm{P} \text { (between } \\
\text { diabetic) } \\
\text { all five } \\
\text { timepoints }\end{array}$ \\
\hline \multicolumn{9}{|l|}{$C R P(m g / l)$} \\
\hline No progression & $2.3(0.9-5.1]$ & $2.3(1.3-5.8)$ & $2.2(1.3-4.5)$ & $1.3(0.7-2.7)$ & $1.1(0.5-1.6)$ & 1.0 & 0.257 & $0.037^{*}$ \\
\hline Progression & $3.8(2.1-9.4)$ & $4.8(2.3-9.5)$ & $2.5(2.0-6.0)$ & $2.1(0.9-3.5)$ & $3.2(0.6-4.4)$ & 0.140 & & \\
\hline Controls & $2.7(1.5-14.6)$ & NA & $2.5(0.9-4.9)$ & $0.5(0.2-1.3)$ & NA & & & \\
\hline \multicolumn{9}{|l|}{$I L-6(p g / m l)$} \\
\hline No progression & $1.1(0.7-2.1)$ & $1.4(0.9-2.4)$ & $2.7(1.8-4.2)$ & $1.6(1.2-2.0)$ & $1.5(0.9-2.2)$ & 1.0 & 0.829 & 0.107 \\
\hline Progression & $1.2(0.7-2.9)$ & $2.2(1.2-3.2)$ & $2.7(1.8-4.8)$ & $1.9(1.0-3.5)$ & $2.0(0.9-7.3)$ & 0.328 & & \\
\hline Controls & $1.2(0.9-1.7)$ & NA & $1.8(0.8-4.1)$ & $1.0(0.6-1.3)$ & NA & & & \\
\hline \multicolumn{9}{|l|}{ VCAM-1 (ng/ml) } \\
\hline No progression & $588(490-776)$ & 487 (411-646) & 717 (532-1164) & $631(540-824)$ & $617(486-841)$ & 1.0 & 0.693 & 0.213 \\
\hline Progression & $571(471-767)$ & $471(363-503)$ & $588(474-757)$ & $622(535-800)$ & 609 (470-908) & 1.0 & & \\
\hline Controls & 736 (621-928) & NA & $535(469-665)$ & 765 (630-950) & NA & & & \\
\hline
\end{tabular}

3 mo $\mathrm{pp}=3$ months postpartum; CRP=C-reactive protein; IL-6: interleukin-6; VCAM-1=vascular cell adhesion molecule-1; Values are median (interquartile range); NA = Not applicable. $P$-values were calculated with repeated measures ANOVA; CRP, IL-6, and VCAM-values were logtransformed to correct skewness.

Table 5 Concentrations of inflammatory markers in Type I diabetic women according to mean HbA1c value $<6.9 \%(n=22)$ or $\geq 6.9 \%$ $(n=17)$ during pregnancy

\begin{tabular}{|c|c|c|c|c|c|c|}
\hline & First trimester & Second trimester & Third trimester & 3 mo $p p$ & 6 mо $p p$ & $\mathrm{P}$ (between diabetics) \\
\hline \multicolumn{7}{|c|}{$C R P(m g / l)$} \\
\hline$<6.9 \%$ & $1.9(0.7-4.0)$ & $2.5(1.2-5.2)$ & $1.8(1.2-3.2)$ & $1.6(0.8-3.1)$ & $0.7(0.4-3.1)$ & $0.038^{*}$ \\
\hline$\geq 6.9 \%$ & $5.1(2.2-8.7)$ & $5.8(2.2-9.4)$ & $4.1(2.0-6.0)$ & $1.3(1.0-3.5)$ & $1.3(0.9-3.7)$ & \\
\hline \multicolumn{7}{|c|}{$I L-6(p g / m l)$} \\
\hline$<6.9 \%$ & $1.1(0.6-2.3)$ & $1.7(0.9-2.4)$ & $2.1(1.5-3.5)$ & $1.7(1.2-2.9)$ & $1.4(0.8-2.2)$ & 0.681 \\
\hline$\geq 6.9 \%$ & $1.2(0.7-2.1)$ & $1.7(1.1-2.6)$ & $3.3(2.4-4.8)$ & $1.5(1.2-2.1)$ & $1.8(1.0-3.1)$ & \\
\hline \multicolumn{7}{|c|}{ VCAM-1 (ng/ml) } \\
\hline$<6.9 \%$ & $632(556-876)$ & $498(437-682)$ & $611(474-1144)$ & 712 (580-891) & $670(544-953)$ & $0.048^{*}$ \\
\hline$\geq 6.9 \%$ & $555(466-583)$ & $460(367-508)$ & $717(532-831)$ & $620(520-712)$ & $500(471-637)$ & \\
\hline
\end{tabular}

Values are median (interquartile range); P-values were calculated with repeated measures ANOVA; CRP, IL-6, and VCAM-values values were logtransformed to correct skewness; *Statistically significant difference.

(not shown). Neither there were any differences in the levels of proinflammatory markers between the groups, when divided according to the highest quartile (25\%) and the three lower quartiles $(75 \%)$ of retinal capillary blood flow (not shown).

\section{Multivariate logistic regression analysis}

In logistic regression analysis with the progression of retinopathy by the third trimester (no change in DCCT compared to at least one step worsening of DCCT) as the dependent variable, none of the studied parameters qualified in the model. Factors such as age of the patient, body mass index (BMI), duration of diabetes, systolic or diastolic blood pressure in the third trimester, mean HbA1c during pregnancy, CRP, IL-6, and VCAM-1 were dropped from the model.

\section{Discussion}

To our knowledge, this is the first report relating the levels of proinflammatory cytokine IL-6, VCAM-1, and CRP protein to progression of retinopathy during Type I diabetic pregnancy. The main finding was that the levels of these systemic mediators are similar in diabetic and nondiabetic women throughout pregnancy 
and postpartum. The levels were often crossing at different time-points. Thus, it is unlikely that a study with a larger material and more statistical power would have revealed biologically meaningful differences between these groups. However, within the group of diabetic women elevated CRP values were associated with progression of retinopathy and worse glycaemic control during pregnancy. According to our study, levels of the studied markers did not explain increased retinal blood flow during diabetic pregnancy.

Normal pregnancy is characterized by generalized leucocyte activation. Peripheral circulation during pregnancy is characterized by an increased percentage of granulocytes and decreased amount of lymphocytes, supporting the hypothesis that innate immune system is elevated and adaptive immune system is suppressed during pregnancy. ${ }^{15}$ Most cytokines are released from lymphocytes and leucocytes. IL-6 production has been reported to be decreased during normal human pregnancy. ${ }^{15}$ However, in our study, levels of IL-6 increased towards the end of pregnancy in both study groups.

In general, Type I diabetes is associated with endothelial dysfunction, and abnormally presented receptor molecules for leucocyte adhesion, the members of the immunoglobulin supergene family. VCAM-1 is known to have a more restricted distribution than intercellular adhesion molecule (ICAM-1), being expressed on vascular endothelium and dendritic cells. ${ }^{16}$ VCAM-1 is abnormally presented on ECs in diabetes mellitus, ${ }_{17}$ and soluble circulating forms of VCAM- 1 and ICAM-1 can be elevated in the blood of diabetic patients. ${ }^{18}$

DR has been suggested to be a low-grade inflammatory disease. ${ }^{19,20}$ Leucocyte-endothelial interaction (leucocyte rolling and adhesion to the capillary endothelium) is known to have a role in the pathogenesis of DR. ${ }^{21-23}$ Levels of soluble VCAM-1 in young subjects with Type I diabetes with no evidence of vascular disease seem not to be elevated..$^{24}$ Instead, VCAM-1 is increased in diabetic patients with microangiopathy (retinopathy), ${ }^{25}$ proliferative retinopathy (PDR) $)^{26,27}$ and with microalbuminuria and overt nephropathy. ${ }^{28}$

In our study, VCAM-1 did not differ between diabetic and normal pregnancy confirming thus a study by Gibson et al (1997) showing that VCAM-1 is not increased abnormally in diabetic women with good glycaemic control during otherwise uncomplicated pregnancy. ${ }^{29}$ Surprisingly, in our patients the VCAM-1 levels were somewhat elevated in those diabetic women with lower HbA1c values compared to those with higher levels during pregnancy and postpartum.
CRP that is produced in the liver, is a marker of systemic inflammation. It has been suggested that there is an association between glycaemic control and systemic inflammation in diabetic patients. In a study by King et al (2003) the likelihood of elevated CRP concentration increased with increasing HbA1c levels. ${ }^{30}$ Previously, increased CRP levels were also observed in Type I diabetic patients without clinical macroangiopathy. ${ }^{4}$ Serum concentrations of IL-6 are known to promote the production of CRP, thus CRP may reflect indirectly the association between IL-6 and DR. ${ }^{31}$ In our study, elevated CRP levels were associated with worsening retinopathy in diabetic women during pregnancy. Additionally, levels of CRP were higher in those diabetic women with worse glycaemic control than in those with better control during pregnancy and postpartum.

The proinflammatory cytokine, IL-6 is a powerful inducer of the hepatic acute-phase response. It has been suggested to be involved in the pathogenesis of Type I diabetes, ${ }^{32}$ although conflicting results have been published with either increased ${ }^{3}$ or normal ${ }^{33}$ levels of IL6 in diabetic patients compared to nondiabetic controls. Recently, elevated systemic levels of IL-6 were detected only in newly diagnosed cases with Type I diabetes, suggesting thus activation of the inflammatory immune response at early stages of the disease..$^{34}$ IL-6 has also been implicated in the pathogenesis of proliferative vitreoretinopathy ${ }^{35}$ and chronic eye inflammation. ${ }^{36}$ However, the role of IL-6 in DR is still unclear. ${ }^{37}$ In a recent study, levels of IL-6 were even below the detection limits of the assay in all diabetic patients and nondiabetic controls, but instead IL-8 was suggested of being related to progression of Type II DR. ${ }^{38}$ Previously, aqueous levels of IL-6 have been shown to correlate significantly with the severity of macular oedema in diabetics. ${ }^{39}$ Vitreous, but not serum, concentrations of IL-6 were higher in PDR than in noninflammatory retinopathy. ${ }^{40}$

In our study, detectable serum levels of IL-6 were found in diabetic and nondiabetic women throughout pregnancy and postpartum, but the levels were comparable in both groups. Our diabetic women were in good metabolic control, and this may explain why we could not find differences between the two study groups. However, during pregnancy and postpartum, IL-6 levels were significantly lower in diabetic women with duration of DM less than 16 years compared to those with longer duration, which partially contradicts the earlier findings. ${ }^{34}$

Accordingly, it seems that VCAM-1 is not elevated in early and moderate forms of DR during pregnancy. We can speculate that in our diabetic women, there was not enough destruction in retinal ECs (IL-6 was not elevated) to launch further inflammatory reaction by attracting leucocytes to attach to the ECs in retinal capillaries. In 
addition, IL-6, CRP, and VCAM-1 were not related to retinal blood flow during diabetic pregnancy.

In conclusion, in our study, the inflammatory mediators were not generally upregulated during diabetic pregnancy in a way that might have explained the tendency of DR to progress during pregnancy. However, our results support further the connection between the proinflammatory serotype, as indicated by elevated CRP and the progression of DR. The role of the specific mediators IL-6 and VCAM-1 in the progression of DR during pregnancy remains, however, unresolved.

\section{Acknowledgements}

This work was supported by the Finnish Eye Foundation, Helsinki; the Friends of the Blind, Helsinki; the Oskar Öflund Foundation, Helsinki; the Maud Kuistila Foundation, Helsinki; the Foundation for Diabetes Research, Tampere; the Paulo Foundation, Helsinki; HUCH Clinical Research Grant (TKK4150), Helsinki, Finland.

\section{References}

1 Thornburg KL Jacobson S-L, Giraud GD, Morton MJ. Hemodynamic changes in pregnancy. Semin Perinatol 2000; 24: 11-14.

2 Hellstedt T, Kaaja R, Teramo K, Immonen I. Macular blood flow during pregnancy in patients with early diabetic retinopathy measured by blue-field entoptic simulation. Graefes Arch Clin Exp Ophthalmol 1996; 234: 659-663.

3 Mohamed-Ali V, Armstrong L, Clarke D, Bolton CH, Pinkney JH. Evidence for the regulation of levels of plasma adhesion molecules by proinflammatory cytokines and their soluble receptors in type 1 diabetes. I Intern Med 2001; 250: 415-421.

4 Schalkwijk CG, Poland DC, van Dijk W et al. Plasma concentration of C-reactive protein is increased in type I diabetic patients without clinical macroangiopathy and correlates with markers of endothelial dysfunction: evidence for chronic inflammation. Diabetologia 1999; 42: 351-357.

5 Ideta R, Yamashita H, Tanaka Y, Kok A, Emers JJ, Drager $\mathrm{AM}$ et al. Roles of cytokines in diabetic retinopathy. Arch Ophthalmol 1999; 117: 700-701.

6 Wolf M, Sandler L, Hsu K, Vossen-Smirnakis K, Ecker JL, Thadhani R. First-trimester C-reactive protein and subsequent gestational diabetes. Diabetes Care 2003; 26: 819-824.

7 Loukovaara S, Harju M, Kaaja R, Immonen I. Retinal capillary blood flow in diabetic and nondiabetic women during pregnancy and postpartum period. Invest Ophthalmol Vis Sci 2003; 44: 1486-1491.

8 Abiko T, Abiko A, Clermont AC, Shoelson B, Horio N, Takahashi $\mathrm{J}$ et al. Characterization of retinal leukostasis and hemodynamics in insulin resistance and diabetes: role of antioxidants and protein kinase-C activation. Diabetes 2003; 52: 829-837.

9 Thomas W, Shen Y, Molitch ME, Steffes MW. Rise in albuminuria and blood pressure in patients who progressed to diabetic nephropathy in the Diabetes Control and Complications Trial. J Am Soc Nephrol 2001; 12: 333-340.

10 Early Treatment Diabetic Retinopathy Study Research Group. Grading diabetic retinopathy from stereoscopic color fundus photographs - an extension of the modified Airlie House classification. EDTRS report number 10. Ophthalmology 1991; 98: 786-806.

11 The Diabetes Control and Complications Trial (DCCT) Research Group. The effect of intensive treatment of diabetes on the development and progression of long-term complications in insulin-dependent diabetes mellitus. N Engl J Med 1993; 329: 977-986.

12 Hemmilä I, Dakubu S, Mukkala V-M, Siitari H, Lövgren T. Europium as a label in time-resolved immunofluorometric assays. Anal Biochem 1984; 137: 335-343.

13 Alfthan H, Schroder J, Fraser R, Koskimies A, Halila H, Stenman UH. Choriogonadotropin and its beta subunit separated by hydrophobic-interaction chromatography and quantified in serum during pregnancy by time-resolved immunofluorometric assays. Clin Chem 1988; 34: 1758-1762.

14 Mason JC, Kapahi P, Haskard DO. Detection of increased levels of circulating intercellular adhesion molecule 1 in some patients with rheumatoid arthritis but not in patients with systemic lupus erythematosus. Lack of correlation with levels of vascular cell adhesion molecule 1. Arthritis Rheum 1993; 36: 519-527.

15 Luppi P, Haluszczak C, Betters D, Richard CA, Trucco M, DeLoia JA. Monocytes are progressively activated in the circulation of pregnant women. J Leukoc Biol 2002; 72: 874-884.

16 Gearing AJ, Hemingway I, Pigott R, Hughes J, Rees AJ, Cashman SJ. Soluble forms of vascular adhesion molecules, e-selectin, ICAM-1, VCAM-1: pathological significance. Ann NY Acad Sci 1992; 667: 324-331.

17 Wautier JL, Schmid-Schonbein GW, Nash GB. Measurement of leukocyte rheology in vascular disease: clinical rationale and methodology International Society of Clinical Hemorheology. Clin Hemorheol Microcirc 1999; 21: 7-24.

18 Fasching P, Veitl M, Rohac M, Streli C, Schneider B, Waldhausl $\mathrm{W}$ et al. Elevated concentrations of circulating adhesion molecules and their association with microvascular complications in insulin-dependent diabetes mellitus. J Clin Endocrinol Metab 1996; 81: 4313-4317.

19 Adamis AP. Is diabetic retinopathy an inflammatory disease? Br J Ophthalmol 2002; 86: 363-365.

20 Gardner TW, Antonetti DA, Barber AJ, Barber AJ, LaNoue KF, Levison SW. Diabetic retinopathy: more than meets the eye. Surv Ophthalmol 2002; 47(Suppl 2): S253-S262.

21 Miyamoto K, Ogura Y, Kenmochi S, Honda Y. Role of leukocytes in diabetic microcirculatory disturbances. Microvasc Res 1997; 54: 43-48.

22 Schröder S, Palinski W, Schmid-Schönbein GW. Activated monocytes and granulocytes, capillary nonperfusion, and neovascularization in diabetic retinopathy. Am J Pathol 1991; 139: $81-100$.

23 Skyrme-Jones R, Meredith IT. Soluble adhesion molecules, endothelial function and vitamin $\mathrm{E}$ in type 1 diabetes. Coron Art Dis 2001; 12: 69-75.

24 Stitt AW, Gardiner TA, Archer DB. Histological and TA ultrastructural investigation of retinal microaneurysm development in diabetic patients. Br J Ophthalmol 1995; 79: 362-367.

25 Matsumoto K, Sera Y, Ueki Y, Inukai G, Niiro E, Miyake S. Comparison of serum concentrations of soluble adhesion 
molecules in diabetic microangiopathy and macroangiopathy. Diab Med 2002; 19: 822-826.

26 Olson JA, Whitelaw CM, McHardy KC, Pearson DW, Forrester JV. Soluble leucocyte adhesion molecules in diabetic retinopathy stimulate retinal capillary endothelial cell migration. Diabetologia 1997; 40: 1166-1171.

27 Refaat GA, Abdel Rasol HA, Baligh MA. A study of soluble adhesion molecules in patients with diabetic retinopathy. Ophthalmic Res 2001; 33, S1;01 (abstract 1466): page 115.

28 Clausen P, Jacobsen P, Rossing K, Jensen JS, Parving HH, Feldt-Rasmussen B. Plasma concentrations of VCAM-1 and ICAM-1 are elevated in patients with Type I diabetes mellitus with microalbuminuria and overt nephropathy. Diab Med 2000; 17: 644-649.

29 Gibson JL, Lyall F, Boswell F, Young A, Maccuish AC, Greer IA. Circulating cell adhesion molecule concentrations in diabetic women during pregnancy. Obstet Gynecol 1997; 90: 874-879.

30 King DE, Mainous III AG, Buchanan TA, Pearson WS. C-reactive protein and glycemic control in adults with diabetes. Diabetes Care 2003; 26: 1535-1539.

31 Baumann H, Gauldie J. Regulation of hepatic acute phase plasma protein genes by hepatocyte stimulating factors and other mediators of inflammation. Mol Biol Med 1990; 7: 147-159.

32 Kishimoto T, Akira S, Taga T. Interleukin-6 and its receptor: a paradigm for cytokines. Science 1992; 258: 593-597.

33 Kulseng B, Vatten L, Espevik T. Soluble tumor necrosis factor receptors in sera from patients with insulindependent diabetes mellitus: relations to duration and complications of disease. Acta Diabetol 1999; 36: 99-105.
34 Erbagci AB, Tarakcioglu M, Coskun Y, Sivasli E, Sibel Namiduru E. Mediators of inflammation in children with type I diabetes: cytokines in type I diabetic children. Clin Biochem 2001; 34: 645-650.

35 Kauffmann DJ, van Meurs JC, Mertens DA, Peperkamp E, Master C, Gerritsen ME. Cytokines in vitreous humor: interleukin-6 is elevated in proliferative vitreoretinopathy. Invest Ophthalmol Vis Sci 1994; 35: 900-906.

36 Franks WA, Limb GA, Stanford MR, Ogilvie J, Wolstencroft RA, Chignell AH et al. Cytokines in human intraocular inflammation. Curr Eye Res 1992; 11(Suppl): 187-191.

37 Funatsu H, Yamashita H, Shimizu E, Kojima R, Hori S Relationship between vascular endothelial growth factor and interleukin-6 in diabetic retinopathy. Retina 2001; 21: 469-477.

38 Doganay S, Evereklioglu C, Er H, Turkoz Y, Sevinc A, Mehmet $\mathrm{N}$ et al. Comparison of serum NO, TNF-alpha, IL-1 beta, sIL-2R, IL-6 and IL-8 levels with grades of retinopathy in patients with diabetes mellitus. Eye 2002; 16: 163-170.

39 Funatsu H, Yamashita H, Noma H, Mimura T, Yamashita T, Hori S. Increased levels of vascular endothelial growth factor and interleukin- 6 in the aqueous humor of diabetics with macular edema. Am J Ophthalmol 2002; 133: 70-77.

40 Yuuki T, Kanda T, Kimura Y, Kotajima N, Tamura J, Kobayashi I et al. Inflammatory cytokines in vitreous fluid and serum of patients with diabetic vitreoretinopathy. J Diabetes Complic 2001; 15: 257-259. 